\title{
The role of measuring airway hyperresponsiveness and inflammatory biomarkers in asthma
}

\author{
Graeme P Currie' \\ Tom C Fardon ${ }^{2}$ \\ Daniel KC Lee ${ }^{3}$ \\ 'Department of Respiratory \\ Medicine, Aberdeen Royal Infirmary, \\ Foresterhill, Aberdeen, Scotland, UK; \\ ${ }^{2}$ Asthma and Allergy Research Group, \\ Ninewells University Hospital and \\ Medical School, Dundee, Scotland, \\ UK; ${ }^{3}$ Department of Respiratory \\ Medicine, Ipswich Hospital, Ipswich, \\ England, UK
}

\begin{abstract}
Asthma is characterized by inflammation and airway hyperresponsiveness, which results in episodic airflow obstruction. It is diagnosed once a compatible clinical history plus objective evidence of diurnal variability in peak expiratory flow or significant reversibility to inhaled bronchodilator is documented. In accordance with current guidelines, measures of airway calibre and symptoms allow patients and clinicians to assess the degree of asthma control and titrate pharmacotherapy. However, these parameters fail to reflect the extent of underlying endobronchial inflammation and airway hyperresponsiveness, which in turn suggests that additional measures of asthma control may be of benefit. This evidence-based review highlights ways by which inflammation and airway hyperresponsiveness can be assessed and how they may provide additional useful information in the diagnosis and management of asthmatic patients.
\end{abstract}

Keywords: asthma, inflammation, airway hyperresponsiveness, eosinophils, corticosteroids, beta-agonists

\section{Introduction}

Asthma is a common condition with a prevalence of up to $20 \%$ in young adult Western populations (ISAAC 1998). The characteristic pathological feature in asthma is underlying inflammation of the bronchial mucosa. As a consequence of the complex interplay between a plethora of inflammatory cells and mediators, the airways exhibit an abnormal response to inhaled bronchoconstrictor stimuli, otherwise known as airway hyperresponsiveness (AHR) (Currie et al 2004). This causes smooth muscle to contract and relax periodically, with the subsequent perception of symptoms. Due to the episodic and reversible nature of the asthmatic inflammatory process, patients intermittently report symptoms such as cough, wheeze, breathlessness, chest tightness, and reduced exercise tolerance.

The diagnosis of asthma is made with a combination of compatible clinical history and objective evidence such as peak expiratory flow (PEF) variability over several weeks of diurnal monitoring. Patients are asked to document serial recordings over a 2-week period; $20 \%$ variability in PEF is considered to be relatively specific, although insensitive as a diagnostic threshold (British Thoracic Society; Scottish Intercollegiate Guidelines Network 2003). A significant degree of reversibility following inhaled bronchodilator or oral corticosteroids can also be useful, especially in patients with impaired lung calibre. For example, a $15 \%$ plus $200 \mathrm{~mL}$ improvement in forced expiratory volume in 1 second $\left(\mathrm{FEV}_{1}\right)$ or $20 \%$ plus $60 \mathrm{~L} / \mathrm{min}$ improvement in PEF is considered classical. Once the diagnosis is secured, treatment is usually indicated and varies from intermittent use of short acting $\beta_{2}$-agonists to combinations of inhaled and oral agents.
Correspondence: Graeme P Currie Department of Respiratory Medicine, Aberdeen Royal Infirmary, Foresterhill, Aberdeen AB25 2ZN, Scotland, UK Tel +44 I22455I 208

Fax +44 I 22455 I 210

Email graeme.currie@nhs.net 
A common problem with the everyday diagnosis of asthma is that many patients - particularly those at the milder end of the spectrum - exhibit normal lung function, implying that significant reversibility to either inhaled bronchodilator or oral corticosteroids cannot be demonstrated. Moreover, due to the inherent variability of the disease process itself, lung function can be normal when patients are not exposed to a bronchoconstrictor stimulus. Indeed, despite normal or near normal lung function, asthmatics often exhibit persistent AHR (Boulet et al 1994; Vignola et al 1998). In such cases of diagnostic uncertainty, current guidelines suggest performing an exercise test in an attempt to demonstrate a significant fall in PEF or $\mathrm{FEV}_{1}$ (British Thoracic Society; Scottish Intercollegiate Guidelines Network 2003), although these can at times be difficult to arrange and are not suitable for all patients.

To compound these problems surrounding diagnosis, monitoring the control of asthma and deciding when to alter antiinflammatory therapy can frequently cause uncertainty. For instance, traditional parameters guiding changes in treatment, such as symptoms and reliever use are by their nature highly subjective and may not correspond to changes in endobronchial inflammation, AHR, or airflow obstruction. Moreover, daily monitoring of PEF requires adequate patient compliance, while a solitary $\mathrm{FEV}_{1}$ measurement at a primary or secondary care clinic may not be representative of airway calibre over the preceding weeks. It may also be artificially elevated when patients have used a short-acting $\beta_{2}$-agonist several hours prior to its measurement.

Additional parameters incorporating the measurement of biomarkers of airway inflammation (Table 1) and AHR are useful adjuncts in both the diagnosis and subsequent management of asthma. They can be useful in avoiding potential pitfalls when assessing subjective measures of asthma control and provide the clinician with an insight into whether underlying inflammation is adequately suppressed and AHR attenuated. This in turn permits a way in which antiinflammatory therapy can be titrated with both potential short- and long-term benefit to the patient. This evidence-

Table I Different inflammatory biomarkers currently used

\section{Inflammatory biomarker}

Sputum eosinophils

Sputum ECP

Blood eosinophils

Blood ECP

Exhaled nitric oxide

Airway hyperresponsiveness to an indirect bronchoconstrictor stimulus

Abbreviations: $\mathrm{ECP}$, eosinophilic cationic protein. based review outlines some problems of conventional measure of asthma control and the different methods of measuring biomarkers of inflammation in asthma, and illustrates ways in which they have been shown to help make the diagnosis and titrate antiinflammatory treatment to achieve better long-term asthma control.

\section{Conventional measures of asthma control}

Measures of airway calibre are frequently recorded indices of asthma control in day-to-day clinical practice. PEF and $\mathrm{FEV}_{1}$ are easily measured in both primary and secondary care settings and minimal training is required for patient and clinician. The forced mid-expiratory flow $\left(\mathrm{FEF}_{25-75}\right)$, considered to be a more sensitive reflection of small airway calibre, tends to be effort-dependent and less reproducible than successive $\mathrm{FEV}_{1}$ measurements. It is important to note that such parameters reflect airway geometry and provide little or no insight into the extent of underlying inflammation or AHR. Indeed, these particular end points tend to be greatly influenced by drugs that act primarily by relaxing airway smooth muscle, such as long-acting $\beta_{2}$-agonists. Although long-acting $\beta_{2}$-agonists are potent bronchodilators, they are devoid of in vivo antiinflammatory activity (Roberts et al 1999; Calhoun et al 2001), which could be of potential concern in long-term asthma control, particularly in patients with erratic adherence to antiinflammatory therapy.

The $\mathrm{FEV}_{1}$ is of limited value in measuring the effects of moderate to high doses of inhaled corticosteroids. For example, in a meta-analysis of 8 randomized placebo controlled trials ( $\mathrm{n}=2324$ subjects), Holt et al (2001) demonstrated that the maximal effect upon $\mathrm{FEV}_{1}$ was observed at daily fluticasone doses of less than $500 \mu \mathrm{g}$ (a beclomethasone equivalent dose of less than $1000 \mu \mathrm{g}$ ). Indeed, at daily doses above $800 \mu \mathrm{g}$ of beclomethasone or equivalent, the dose-response curve for beneficial effects becomes flat (in terms of lung function), while for systemic adverse effects it becomes significantly steeper (Lipworth 1999). In another meta-analysis of 25 studies, the doseresponse effect of high doses of inhaled corticosteroids $(\geq 1000 \mu \mathrm{g} /$ day) was compared with low-to-medium doses $(<1000 \mu \mathrm{g} /$ day $)$ in terms of AHR to bronchoconstrictor stimuli (Currie, Fowler, et al 2003). In this study, high doses of inhaled corticosteroids conferred significantly superior attenuation of AHR (a 2.2 doubling dose/concentration shift) than lower doses (a 1.3 doubling dose/concentration shift). This highlights the more sensitive nature of assessment of 
AHR compared with $\mathrm{FEV}_{1}$ in terms of effects of inhaled corticosteroids.

In a study of moderate to severe asthmatics, Pauwels et al (1997) demonstrated an additive effect on frequency of severe exacerbations by formoterol, over and above the beneficial effect already observed with low and medium doses of budesonide. In other words, budesonide reduced frequency of exacerbations by its antiinflammatory effect, while formoterol produced a further reduction by stabilizing airway smooth muscle (Currie, Jackson, et al 2003). In the same study, the additive effect of formoterol to budesonide $200 \mu \mathrm{g} /$ day on severe exacerbation rates over 1 year, was smaller than optimizing the inhaled corticosteroid dose from $200 \mu \mathrm{g} /$ day to $800 \mu \mathrm{g} /$ day (a $26 \%$ versus $49 \%$ reduction in exacerbations, respectively). Moreover, there was a disconnection between lung function and exacerbations; in other words, despite a significant reduction in exacerbations, $\mathrm{FEV}_{1}$ and $\mathrm{PEF}$ were unchanged when comparing budesonide $200 \mu \mathrm{g} /$ day with budesonide $800 \mu \mathrm{g} /$ day. This indicates that when optimizing the dose of inhaled corticosteroid, lung function is relatively distant from the underlying inflammatory process and not always related to more long-term effects.

In another study, montelukast was administered to mildto-moderate asthmatics receiving $500 \mu \mathrm{g} /$ day of fluticasone plus salmeterol (Currie, Lee, et al 2003). Despite no change in $\mathrm{FEV}_{1}$ or PEF, the addition of montelukast did confer significant reductions in inflammatory biomarkers including AHR to adenosine 5-monophoshate (AMP), exhaled nitric oxide (NO), and blood eosinophils (all $\mathrm{p}<0.05)$. This dissociation between such inflammatory biomarkers and lung function, further demonstrates that the latter is relatively distant from the underlying inflammatory process. As a consequence, potential benefits of antiinflammatory therapy may be missed when patients and clinicians titrate therapy according to serial lung function measurements. In another randomized placebo controlled study of mild persistent asthmatics (mean $\mathrm{FEV}_{1} 80 \%$ predicted), the effects of fluticasone $1000 \mu \mathrm{g}$ /day was compared with half the dose in combination with salmeterol (Currie, Bates, et al 2003). Optimizing the inhaled corticosteroid dose conferred superiority $(\mathrm{p}<0.05)$ compared with half the dose combined with salmeterol in terms of inflammatory biomarkers but not lung function (Figure 1). This finding again highlights the fact that monitoring lung function alone may miss potentially beneficial effects of antiinflammatory therapy, further suggesting that it is a relatively downstream consequence of the asthmatic inflammatory process. Thus, (a)

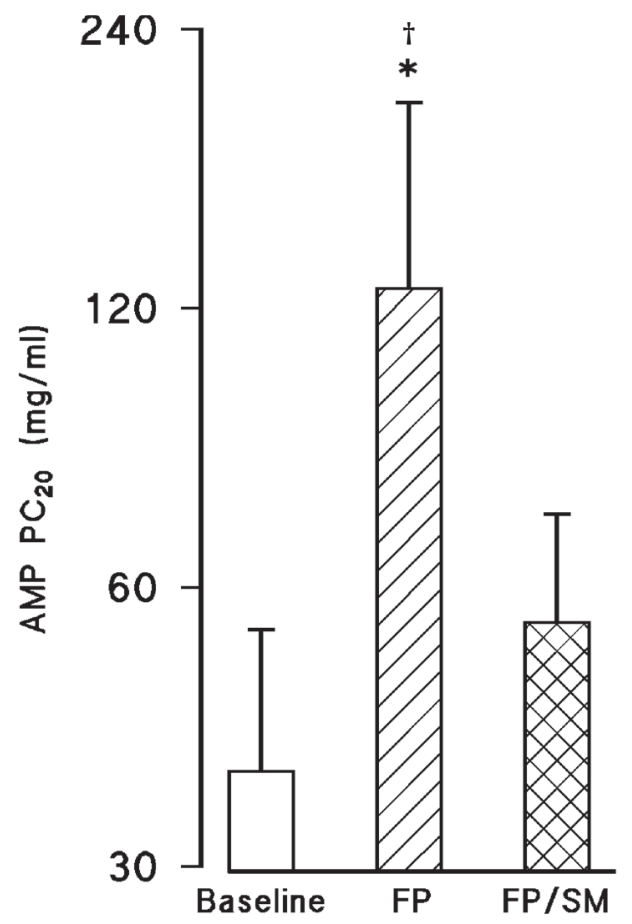

(b)

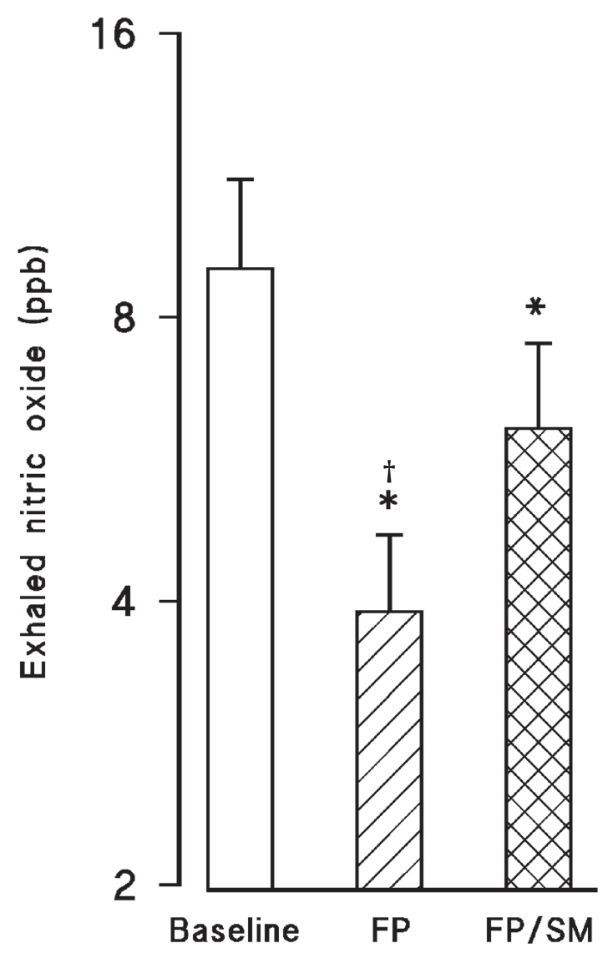

Figure I Absolute geometric mean (geometric SE) for (a) $\mathrm{AMP} \mathrm{PC}_{20}$ and (b) exhaled $\mathrm{NO}$ at baseline and after treatment with daily doses of fluticasone propionate $500 \mu \mathrm{g}$ (FP; hatched bars) and fluticasone propionate $250 \mathrm{\mu g} / \mathrm{salmeterol}$ $50 \mu \mathrm{g} /$ combination inhaler (FP + SM; double hatched bars). *Denotes significant $(p<0.05)$ difference from baseline, $\uparrow$ denotes significant $(p<0.05)$ difference between randomized treatments. Source: Currie GP, Bates CE, Lee DK, et al. 2003. Effects of fluticasone plus salmeterol versus twice the dose of fluticasone in asthmatic patients. Eur J Clin Pharmacol, 59:I I-15. Reproduced with permission from Springer. Abbreviations: AMP, adenosine 5-monophoshate; NO, exhaled nitric oxide. 
while end points such as lung function are of undoubted value, clinicians must not lose sight of the basic pathophysiological hallmarks of the asthma syndrome (ie, AHR and inflammation), which may in turn be responsible for continuing symptoms and the morbidity associated with uncontrolled asthma.

\section{Airway hyperresponsiveness to bronchoconstrictor stimuli}

AHR results in episodic bronchoconstriction and is one of the hallmark features of asthma (Currie et al 2004). It is defined as abnormal airway narrowing in response to a provoking stimulus. AHR can be assessed pharmacologically with methacholine, histamine, mannitol, and AMP or using naturally occurring physical stimuli, for example, hyperventilation with cold air and exercise. It can be regarded as a consequence of inflammation, and is often linked to the degree of underlying inflammation (Wardlaw et al 1988; Robinson et al 1993; Gibson et al 2000).

From a practical point of view, bronchoprovocation is carried out using doubling doses or concentrations (twofold increments) of a given stimulus. At regular intervals (usually several minutes depending on the protocol) the best of several $\mathrm{FEV}_{1}$ measurements is recorded. The procedure is usually terminated after a predetermined fall in $\mathrm{FEV}_{1}$ is achieved (often a 20\% fall). Construction of a log doseresponse curve is followed by linear interpolation, allowing the provocative dose or concentration of stimulant causing a $20 \%$ fall in $\mathrm{FEV}_{1}$ to be calculated $\left(\mathrm{PD}_{20}\right.$ or $\left.\mathrm{PC}_{20}\right)$. Recent data have shown that calculation of a $\mathrm{PD}_{15}$ or $\mathrm{PC}_{15}$ (ie, the dose or concentration causing a $15 \%$ fall in $\mathrm{FEV}_{1}$ ) can produce similar results as compared with when $\mathrm{PD}_{20}$ or $\mathrm{PC}_{20}$ are calculated (Fardon, Currie, et al 2004; Fardon TC, Fardon EJ, et al 2004). This in turn reduces the length of bronchial challenge time, minimizes the chance of a precipitous fall in $\mathrm{FEV}_{1}$ and means that patients inhale smaller doses or concentrations of stimulant. At the completion of a bronchial challenge test, patients are usually given a short acting $\beta_{2}$-agonist to quicken their return to pre-test $\mathrm{FEV}_{1}$ or allowed to recover spontaneously.

It is important to point out that bronchial challenge tests do have several drawbacks: they can be difficult to organize, require access to specialist equipment, and can be timeconsuming, although an abbreviated methacholine challenge test can take less than 30 minutes (Cockcroft et al 2001).

In the laboratory, bronchial provocation tests are used to assess the presence and severity of AHR and provide information on effects of treatment. Currently however, assessing AHR is principally carried out in clinical research settings and very infrequently in the day-to-day diagnosis or management of asthma. Histamine and methacholine are commonly used direct bronchoconstrictor stimuli, which act directly upon effector cells such as airway smooth muscle causing contraction and narrowing of the airway. In contrast, indirectly acting bronchoconstrictor stimuli (for example, AMP, mannitol, and hypertonic saline) act indirectly upon primed mast cells and neural pathways causing release of inflammatory mediators such as histamine and leukotrienes (Lee et al 2003). This in turn leads to smooth muscle contraction. Assessing AHR to indirect stimuli tends to be better correlated with the degree of underlying airway inflammation, particularly in relation to sputum eosinophils and exhaled NO (van Den Toorn et al 2000; Van Den Berge et al 2001). Moreover, the improvements in $\mathrm{AMP} \mathrm{PC}_{20}$ are greater with antiinflammatory therapy than effects upon the methacholine $\mathrm{PD}$ or $\mathrm{PC}_{20}\left(\mathrm{O}^{\prime}\right.$ Connor et al 1992; Wilson and Lipworth 2000).

(a)

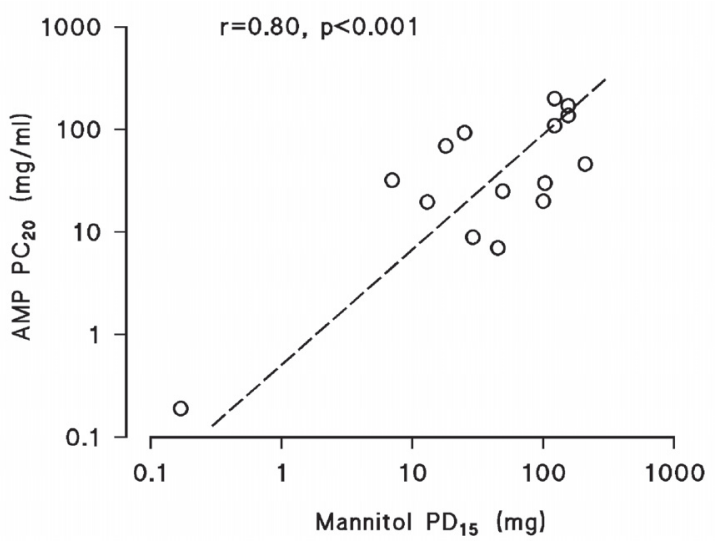

(b)

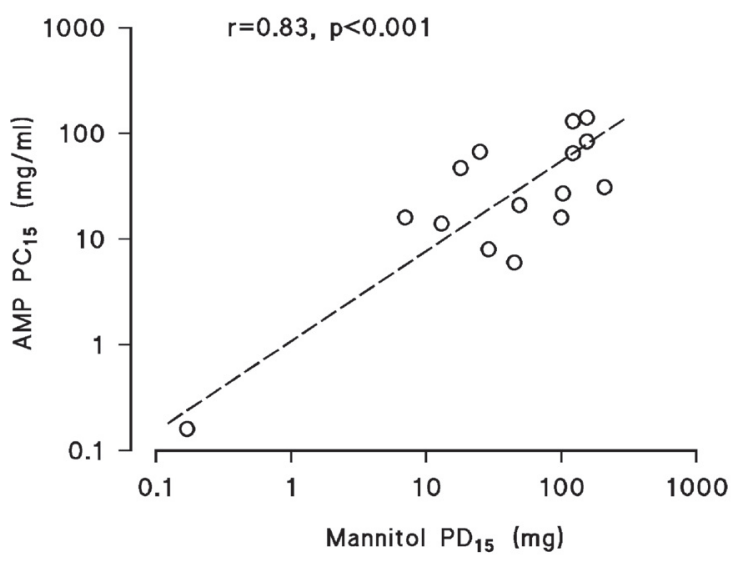

Figure 2 Correlations between (a) AMP PC 20 versus mannitol PD ${ }_{15}$, (b) AMP $P_{15}$ versus mannitol PD ${ }_{15}$. Source: Currie GP, Haggart K, Brannan JD, et al. 2003. Relationship between airway hyperresponsiveness to mannitol and adenosine monophosphate. Allergy, 58:762-6. Reproduced with permission from Blackwell Publishers. Abbreviations: AMP, adenosine 5-monophoshate. 
Mannitol is a potentially useful bronchoconstrictor stimulus and can be used to assess AHR (Anderson et al 1997). When given as a dry powder, inhaled mannitol increases the surface osmolarity of the bronchial mucosa resulting in the release of inflammatory mediators from a variety of cells. From a practical point of view, mannitol bronchoprovocation does not require a nebulizer and can be performed using a simple handheld inhaler device. Moreover, when compared with other indirect challenges (eg, exercise), the use of mannitol results in a more controlled reduction of lung function. This is due to the carefully observed sequential fall in $\mathrm{FEV}_{1}$ after each inhalation, allowing the procedure to be stopped immediately after the desired reduction and reduces the chance of excessive airway narrowing. Furthermore, the degree of AHR to inhaled mannitol correlates closely to the airway response following inhaled AMP (Figure 2) (Currie, Haggart, et al 2003).

\section{Inflammatory biomarkers in asthma \\ Eosinophils}

Eosinophilic inflammation is well recognized to be a major feature in the pathogenesis of asthma. Following eosinophilopoiesis in bone marrow, regulated by interleukin (IL)-3, IL-5, and GM-CSF (Warlaw 1999), eosinophils migrate from the circulation to pulmonary airways in response to various cytokines. Peripheral blood eosinophils are increased in asthma and fall after introduction of inhaled corticosteroids (Evans et al 1993; Currie, Syme-Grant, et al 2003); however, it is pertinent to be aware that they are also raised in other conditions.

With more invasive assessment, it has been demonstrated that eosinophil levels in induced sputum can provide more direct and useful information in the evaluation of asthma (Parameswaran and Hargreave 2001). Patients are pretreated with inhaled salbutamol and then undergo three sequential inhalations of $3 \%, 4 \%$, and $5 \%$ hypertonic saline with 5-10 minutes of each concentration (Parameswaran and Hargreave 2001). Salivary contamination is minimized by asking the subject to blow their nose and rinse their mouth prior to expectorating at 5-10-minute intervals. Inconsistent results in terms of a step-wise relationship between inhaled corticosteroid dose versus reduction in sputum eosinophils have been produced (Jatakanon et al 1999; Taylor et al 1999). For example, dose-related changes were observed in sputum eosinophils with fourfold increments in inhaled budesonide doses (Jatakanon et al 1999), although in contrast Taylor et al (1999) failed to demonstrate such a dose-response relationship. In the latter study however, a dose-response relationship for AHR to AMP was observed following treatment with 100,400 , and $1600 \mu \mathrm{g} / \mathrm{day}$ of ciclesonide.

Eosinophilic cationic protein (ECP) is one of several granular proteins released from eosinophils, and is a reflection of activated circulating eosinophils. However, the use of serum ECP as a non-invasive guide in asthma management has produced inconsistent and generally disappointing results (Wever et al 1994; Ferguson et al 1995; Meijer et al 2002). For example, in a study of 20 asthmatics who had been corticosteroid free for 4 weeks, the addition of $200 \mu \mathrm{g} /$ day of inhaled fluticasone for 2 weeks failed to significantly reduce serum ECP levels (Currie, Syme-Grant, et al 2003). In the same study, a small though significant reduction (1.3-fold) in blood eosinophils was observed (Figure 3). It is important to note that more impressive changes in sputum eosinophils (4.3-fold), exhaled NO (1.8-fold), AHR to methacholine (2.3-fold), and sputum ECP (2.2-fold) were observed (Figure 3). This in turn implies that systemic indices of asthma control such as serum ECP and blood eosinophils are relatively distant from the asthmatic inflammatory process occurring in the airways. As a consequence, they are unable to provide a sufficiently strong signal from which the effects of inhaled corticosteroids or other antiinflammatory therapy can be observed.

\section{Exhaled nitric oxide}

NO is produced from respiratory epithelium and inflammatory cells by several NO synthase isoforms. Inflammatory cells are probably the major source of NO over and above airway epithelium and in patients with asthmatic airway inflammation, the expression of NO synthases is increased. As a consequence, elevated levels of exhaled NO are often detected in asthmatic individuals compared with matched controls (Kharitonov et al 1994). Previous data have demonstrated that the level of exhaled NO is significantly correlated with eosinophils in both bronchoalveolar lavage and induced sputum (Jatakanon et al 1998; Warke et al 2002). In a cross-sectional study by Sippel et al (2000), exhaled NO was not significantly correlated to $\mathrm{FEV}_{1}$, again demonstrating that measures of airway calibre are disconnected from the asthmatic inflammatory process.

Exhaled NO is reduced by both steroidal and nonsteroidal antiinflammatory treatments such as leukotriene receptor antagonists (Bisgaard et al 1999; Bratton et al 1999; Currie, Lee, et al 2003). However, the dose-response curve 
(a)

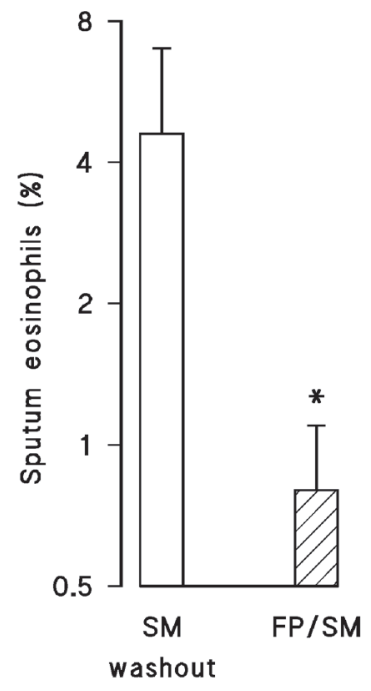

(c)

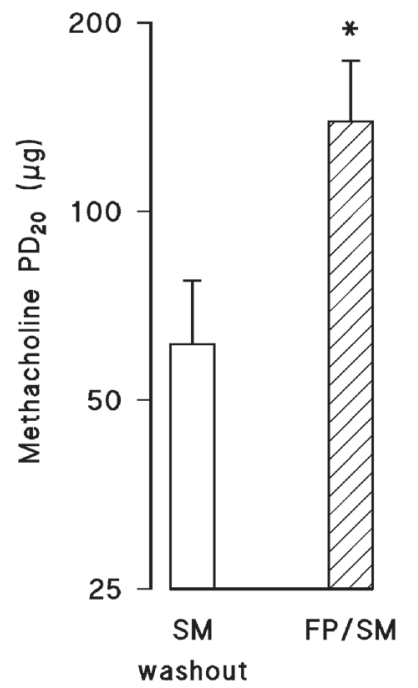

(b)

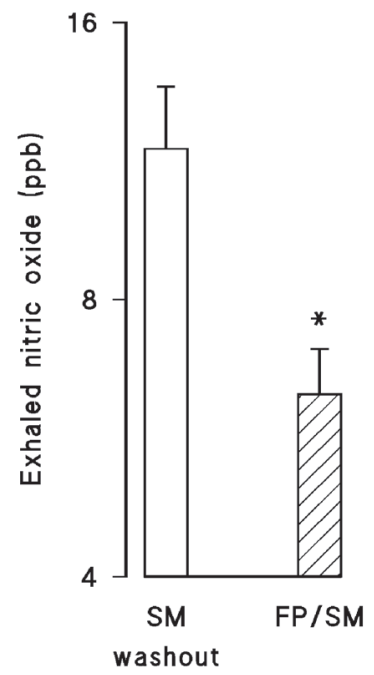

(d)

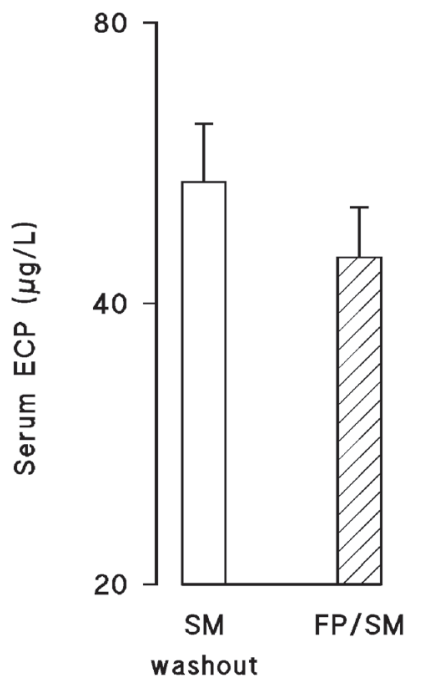

Figure 3 Bargraphs illustrate absolute values after salmeterol $100 \mu g /$ day (SM) washout (empty bars) and after 2 weeks of fluticasone $200 \mu g /$ salmeterol $100 \mu g /$ day (FP/SM) treatment (hatched bars) for (a) sputum eosinophils, (b) exhaled NO, (c) methacholine $\mathrm{PD}_{20}$, and (d) serum ECP. *Denotes significant ( $\left.<<0.05\right)$ difference from salmeterol washout. Source: Currie GP, Syme-Grant NJ, McFarlane LC, et al. 2003. Effects of low dose fluticasone/salmeterol combination on surrogate inflammatory markers in moderate persistent asthma. Allergy, 58:602-7. Reproduced with permission from Blackwell Publishers. Abbreviations: ECP, eosinophilic cationic protein; NO, exhaled nitric oxide.

for effects of inhaled corticosteroids upon exhaled NO becomes flat at daily doses greater than $800 \mu \mathrm{g}$ of budesonide (Wilson and Lipworth 2000). As a consequence, this finding may well limit its sensitivity as a marker for disease severity and a measure of disease progression in patients using higher doses of inhaled corticosteroids.

\section{Diagnosis of asthma}

\section{Airway hyperresponsiveness}

Assessing AHR to methacholine is a recognized tool in the diagnosis in asthma (Crapo et al 2000). Indeed, in patients with symptoms but normal airway responsiveness, asthma is unlikely to be the diagnosis. Although AHR is one of the hallmark features of asthma, it can be demonstrated in other disease processes, such as chronic obstructive pulmonary disease, congestive cardiac failure, cystic fibrosis, allergic rhinitis (all without the presence of asthma) (Ramsdell et al 1982; Yan et al 1985; Du Toit et al 1986). Methacholine challenge is most useful in patients whose pre-test probability score for asthma is $30 \%-70 \%$, or in other words when diagnostic uncertainty exists (Perpina et al 1993). In such situations, clinicians are unable to predict the extent of AHR to methacholine (Dales et al 1988), in turn suggesting that there are few clinical clues to allow accurate 
assessment of AHR. When compared with PEF variability and bronchodilator reversibility, assessing the degree of AHR to methacholine has proved to be a more useful aid in the diagnosis of asthma (Goldstein et al 2001; Hunter et al 2002). Whether measuring AHR to indirect bronchoconstrictor stimuli provides further benefit and certainty in diagnosis requires prospective evaluation.

Several contraindications exist to performing bronchial challenge tests such as moderately severe airflow obstruction, pregnancy and lactation, uncontrolled hypertension, and inability to correctly perform spirometry (Crapo et al 2000). The American Thoracic Society has also suggested stratifying the degree of AHR to methacholine according to the $\mathrm{PC}_{20}$ value. For example, normal AHR is considered present when the $\mathrm{PC}_{20}$ is $>16 \mathrm{mg} / \mathrm{mL}$, while borderline, mild, and moderate-to-severe AHR is present when respective values are $4.0-1.6 \mathrm{mg} / \mathrm{mL}, 1.0-4.0 \mathrm{mg} / \mathrm{mL}$, and $<1 \mathrm{mg} / \mathrm{mL}$ (Crapo et al 2000).

\section{Exhaled nitric oxide}

In the laboratory setting, the measurement of exhaled NO is quick and easy. For instance, patients are asked to exhale through a mouthpiece for between 5 and 20 seconds to eliminate dead space and nasal contamination, and the end tidal NO can be obtained as the plateau value at the end of exhalation (Kharitonov et al 1996). From a diagnostic point of view, NO has been shown to effectively discriminate between asthmatic and non-asthmatic subjects (Alving et al 1993; Kharitonov et al 1994). In another study, Taylor et al (1999) evaluated 47 consecutive patients with symptoms suggestive of asthma, and sensitivities and specificities were obtained for PEF, spirometry, and inflammatory biomarkers, in addition to changes in these parameters after a corticosteroid trial. Sensitivities for each of the conventional tests $(0 \%-47 \%)$ were significantly lower than for exhaled NO (88\%) and sputum eosinophils (86\%), while results for conventional tests of airway calibre were not improved following a corticosteroid trial. Thus, exhaled NO and measurement of induced sputum eosinophils were superior to conventional approaches, with the implication that incorporating NO levels into the initial assessment of patients with possible asthma can be a useful adjunct.

\section{Titrating asthma therapy}

Measuring AHR has been shown to be a useful guide in the management of asthma. In a parallel group study involving 75 adults, Sont et al (1999) titrated the dose of inhaled corticosteroid according to conventional measures of airway calibre in conjunction with AHR to methacholine. Patients in whom additional AHR was assessed had fewer exacerbations and symptoms, superior spirometry, and a reduction in thickness of subepithelial reticular layer at bronchoscopic lung biopsy. Despite their observations, the exact association between inflammation and AHR remains unclear and, at times, contentious. It is without doubt that assessment of AHR is a useful non-invasive tool and provides complementary information to that of more conventional outcome measures. Compared with the use of direct agents, assessing AHR to indirect bronchoconstrictor stimuli is superior in the detection of the changes associated with inflammation (O'Connor et al 1992; Wilson and Lipworth 2000). Indeed, perhaps in the study by Sont et al (1999), even better long-term control of asthma might have been achieved if they had evaluated AHR using agents such as AMP or mannitol.

Green et al (2002), evaluated whether an asthma management strategy targeted against sputum eosinophils could lead to better asthma control than using standard guidelines alone. In this prospective study, 74 patients with moderate-to-severe asthma were randomized to have treatment altered on the basis of symptoms plus sputum eosinophil count or according to conventional measures alone. It was discovered that the sputum eosinophil count was $63 \%$ lower over 12 months in the eosinophil management group than in the conventional management group $(p=0.002)$. Moreover, those in the sputum management group had fivefold fewer severe asthma exacerbations than patients treated according to standard guidelines (35 versus $109, \mathrm{p}=0.01$ ).

Despite transforming the management of asthma, inhaled corticosteroids exhibit adverse effects in a dose-dependent fashion. Current guidelines suggest back titration of asthma therapy once symptoms and lung function have been stable over a preceding 3-6-month period (British Thoracic Society; Scottish Intercollegiate Guidelines Network 2003). Leuppi et al (2001) evaluated putative markers, which could be helpful in guiding clinicians in the step wise reduction of inhaled corticosteroid doses. They evaluated 50 patients with well controlled asthma (median daily inhaled corticosteroid dose of $1000 \mu \mathrm{g}$ ). The inhaled corticosteroid dose was halved every 2 months; AHR to mannitol and histamine, spirometry, exhaled NO, and sputum eosinophils were measured at baseline and at monthly intervals. Thirtynine subjects experienced an asthma exacerbation, while seven subjects were successfully weaned off inhaled 
corticosteroids. The most important predictors of failure of inhaled corticosteroid reduction were the demonstration of AHR to both histamine and mannitol at baseline $(p=0.039)$, and AHR to mannitol during the dose reduction phase of the study $(p=0.02)$. In the same study, AHR to mannitol was more pronounced and there were more sputum eosinophils present before a failed reduction of inhaled corticosteroid dose. In contrast, there were no significant differences in symptoms, spirometry, or NO between periods where failed reduction of doses occurred. These findings suggest that knowledge of the extent of AHR to mannitol or extent of sputum eosinophilia may be useful in back titration of inhaled corticosteroids.

In another study of 78 patients with mild-moderate asthma, the ability of exhaled NO in predicting loss of control in asthma following steroid withdrawal was evaluated (Jones et al 2001). Comparisons were made against sputum eosinophils and AHR to hypertonic saline. Patients had their inhaled corticosteroids withdrawn until their asthma became uncontrolled (60 patients) or for a maximum of 6 weeks. Significant correlations between the changes in exhaled NO and symptoms $(\mathrm{p}<0.0001), \mathrm{FEV}_{1}$ $(\mathrm{p}<0.002)$, sputum eosinophils $(\mathrm{p}<0.0002)$, and saline $\mathrm{PD}_{15}$ $(\mathrm{p}<0.0002)$ were observed. Isolated measurements and also changes in exhaled NO levels had positive predictive values of over $80 \%$ for predicting loss of asthma control. Perhaps not surprisingly, results were similar to those obtained by measuring sputum eosinophils and AHR to saline. Thus, knowledge of sputum eosinophilia together with exhaled NO levels and AHR can be useful in allowing asthma therapy to be successfully back titrated.

\section{Conclusion}

It can be seen therefore that better asthma control can be achieved when an inflammatory biomarker is included in the algorithm by which asthma therapy is tailored. Indeed, concomitant assessment of AHR and other inflammatory biomarkers are undoubtedly of value in diagnosis, reducing exacerbation frequency and prevention of airway remodeling. However, it does have to be borne in mind that asthma guidelines and clinical tools by which treatment is titrated require to be practical, evidence-based, and usable in everyday real life. Not only could this be important in terms of appropriate dosing regimes, but also important in back titrating therapy. Unfortunately, there is no widely accepted and straightforward method of identifying airway inflammation or AHR, and the methods described above tend to be preserved for research purposes and use in specialized centres only.

Inhaled corticosteroids are the first line treatment in the management of asthma. In adults, the recommended dose is between $400-800 \mu \mathrm{g} /$ day of beclomethasone or equivalent (British Thoracic Society; Scottish Intercollegiate Guidelines Network 2003). Other than clinical markers of asthma severity such as symptoms and lung function, there is little else to guide clinicians as to when a long-acting $\beta_{2}$ agonist or other second line agent such as a leukotriene receptor antagonist should be started. In this respect, a noninvasive inflammatory biomarker could help in the management of patients. For example, it is highly likely that in some patients, only low doses of inhaled corticosteroid ( $400 \mu \mathrm{g} /$ day) are sufficient to suppress airway inflammation, and that the addition of a long-acting $\beta_{2}$ agonist is perfectly acceptable in patients with persistent symptoms - especially in those with impaired lung function. Conversely, some patients with more severe endobronchial inflammation may well require daily doses greater than $800 \mu \mathrm{g}$ of beclomethasone or equivalent before inflammation is adequately suppressed. The decision to start second line therapy can often be fairly arbitrary and knowledge of whether inflammation is adequately suppressed would be useful in ensuring optimum benefit and prevention of more long-term adverse sequelae such as airway remodeling. In the ideal world, clinicians would have access to a simple test that would assist them in this respect; characteristics of the "ideal" inflammatory biomarker are shown in Table 2.

The more widespread use of such a tool would also be of value in patients already maintained on inhaled corticosteroids plus other second line therapy. For example, an inhaled corticosteroid combined with a long-acting $\beta_{2}$ agonist in a single inhaler is becoming a more popular way in which potent antiinflammatory and bronchodilator therapy, respectively, is delivered to the lungs. This in turn means that fewer devices and inhalations are required for the patient with subsequent potential benefit in terms of adherence. It is important to note however, that such combination inhalers contain fixed doses of two types of drug, implying that it is more difficult to alter the dose of antiinflammatory therapy without altering the dose of longacting $\beta_{2}$-agonist. This may mean that some patients take insufficient or excessive amounts of inhaled corticosteroids. When reviewed at clinic, it might be advantageous for patients using such combination inhalers to undergo measurement of a reliable inflammatory biomarker. In 
Table 2 Characteristic features of the ideal inflammatory biomarker in asthma

The ideal inflammatory biomarker
Raised only in asthma
Raised only when endobronchial inflammation is present
Simple and cheap to measure
Easy to measure in primary and secondary care settings
Patient acceptability
Linear reduction on institution of antiinflammatory therapy with clear
cut dose-response effect
Demonstrated to provide superior clinical control when used along
with conventional measures than the latter alone

Source: Currie GP, Lee DK, Wilson AM. 2005. Effects of dual therapy with corticosteroids plus long acting $\beta_{2}$-agonists in asthma. Respir Med. In press. Reproduced with permission from Elsevier Science.

patients with persistent symptoms and evidence of ongoing inflammation, further antiinflammatory treatment - with either a higher inhaled corticosteroid dose or leukotriene receptor antagonist - could be instituted. In asymptomatic patients and no evidence of ongoing inflammation, the inhaled corticosteroid dose could be tapered and the patient reassessed several months later.

It may well be that evaluating asthma control with inflammatory biomarkers and AHR in "real life" settings along with conventional parameters will lead to better longterm outcomes, including effects upon airway remodeling and minimization of systemic adverse sequelae. This may in turn reduce the burden of chronic asthma in primary and secondary care settings alike.

\section{References}

Alving K, Weitzberg E, Lundberg JM. 1993. Increased amount of nitric oxide in exhaled air of asthmatics. Eur Respir J, 6:1368-70.

Anderson SD, Brannan J, Spring J, et al. 1997. A new method for bronchialprovocation testing in asthmatic subjects using a dry powder of mannitol. Am J Respir Crit Care Med, 156:758-65.

Bisgaard H, Loland L, Oj JA. 1999. NO in exhaled air of asthmatic children is reduced by the leukotriene receptor antagonist montelukast. $\mathrm{Am} \mathrm{J}$ Respir Crit Care Med, 160:1227-31.

Bratton DL, Lanz MJ, Miyazawa N, et al. 1999. Exhaled nitric oxide before and after montelukast sodium therapy in school-age children with chronic asthma: a preliminary study. Pediatr Pulmonol, 28:402-7.

British Thoracic Society; Scottish Intercollegiate Guidelines Network. 2003. British guideline on the management of asthma. Thorax, 58 Suppl 1:i1-94.

Boulet LP, Turcotte H, Brochu A. 1994. Persistence of airway obstruction and hyperresponsiveness in subjects with asthma remission. Chest, 105:1024-31.

Calhoun WJ, Hinton KL, Kratzenberg JJ. 2001. The effect of salmeterol on markers of airway inflammation following segmental allergen challenge. Am J Respir Crit Care Med, 163:881-6.

Cockcroft DW, Marciniuk DD, Hurst TS, et al. 2001. Methacholine challenge: test-shortening procedures. Chest, 120:1857-60.
Crapo RO, Casaburi R, Coates AL, et al. 2000. Guidelines for methacholine and exercise challenge testing-1999. This official statement of the American Thoracic Society was adopted by the ATS Board of Directors, July 1999. Am J Respir Crit Care Med, 161:309-29.

Currie GP, Bates CE, Lee DK, et al. 2003. Effects of fluticasone plus salmeterol versus twice the dose of fluticasone in asthmatic patients. Eur J Clin Pharmacol, 59:11-15.

Currie GP, Fowler SJ, Lipworth BJ. 2003. Dose response of inhaled corticosteroids on bronchial hyperresponsiveness: a meta-analysis. Ann Allergy Asthma Immunol, 90:194-8.

Currie GP, Haggart K, Brannan JD, et al. 2003. Relationship between airway hyperresponsiveness to mannitol and adenosine monophosphate. Allergy, 58:762-6.

Currie GP, Jackson CM, Lipworth BJ. 2004. Does bronchial hyperresponsiveness in asthma matter? J Asthma, 41:247-58.

Currie GP, Jackson CM, Ogston SA, et al. 2003. Airway-stabilizing effect of long-acting beta2-agonists as add-on therapy to inhaled corticosteroids. QJM, 96:435-40.

Currie GP, Lee DK, Haggart K, et al. 2003. Effects of montelukast on surrogate inflammatory markers in corticosteroid-treated patients with asthma. Am J Respir Crit Care Med, 167:1232-8.

Currie GP, Lee DK, Wilson AM. 2005. Effects of dual therapy with corticosteroids plus long acting $\beta_{2}$-agonists in asthma. Respir Med. In press.

Currie GP, Syme-Grant NJ, McFarlane LC, et al. 2003. Effects of low dose fluticasone/salmeterol combination on surrogate inflammatory markers in moderate persistent asthma. Allergy, 58:602-7.

Dales RE, Nunes F, Partyka D, et al. 1988. Clinical prediction of airways hyperresponsiveness. Chest, 93:984-6.

Du Toit JI, Woolcock AJ, Salome CM, et al. 1986. Characteristics of bronchial hyperresponsiveness in smokers with chronic air-flow limitation. Am Rev Respir Dis, 134:498-501.

Evans PM, O’Connor BJ, Fuller RW, et al. 1993. Effect of inhaled corticosteroids on peripheral blood eosinophil counts and density profiles in asthma. J Allergy Clin Immunol, 91:643-50.

Fardon T, Currie G, Lee D, et al. 2004. Lower thresholds for bronchial challenge testing. Allergy, 59:1125-6.

Fardon TC, Fardon EJ, Hodge MR, et al. 2004. Comparative cutoff points for adenosine monophosphate and methacholine challenge testing. Ann Allergy Asthma Immunol, 93:365-72.

Ferguson AC, Vaughan R, Brown H, et al. 1995. Evaluation of serum eosinophilic cationic protein as a marker of disease activity in chronic asthma. J Allergy Clin Immunol, 95:23-8.

Gibson PG, Saltos N, Borgas T. 2000. Airway mast cells and eosinophils correlate with clinical severity and airway hyperresponsiveness in corticosteroid-treated asthma. J Allergy Clin Immunol, 105:752-9.

Goldstein MF, Veza BA, Dunsky EH, et al. 2001. Comparisons of peak diurnal expiratory flow variation, postbronchodilator $\mathrm{FEV}_{1}$ responses, and methacholine inhalation challenges in the evaluation of suspected asthma. Chest, 119:1001-10.

Green RH, Brightling CE, McKenna S, et al. 2002. Asthma exacerbations and sputum eosinophil counts: a randomised controlled trial. Lancet, 360:1715-21

Holt S, Suder A, Weatherall M, et al. 2001. Dose-response relation of inhaled fluticasone propionate in adolescents and adults with asthma: meta-analysis. BMJ, 323:253-6.

Hunter CJ, Brightling CE, Woltmann G, et al. 2002. A comparison of the validity of different diagnostic tests in adults with asthma. Chest, 121:1051-7.

[ISAAC] The International Study of Asthma and Allergies in Childhood Steering Committee. 1998. Worldwide variations in the prevalence of asthma symptoms: the International Study of Asthma and Allergies in Childhood (ISAAC). Eur Respir J, 12:315-35. 
Jatakanon A, Kharitonov S, Lim S, et al. 1999. Effect of differing doses of inhaled budesonide on markers of airway inflammation in patients with mild asthma. Thorax, 54:108-14.

Jatakanon A, Lim S, Kharitonov SA, et al. 1998. Correlation between exhaled nitric oxide, sputum eosinophils, and methacholine responsiveness in patients with mild asthma. Thorax, 53:91-5.

Kharitonov SA, Chung KF, Evans D, et al. 1996. Increased exhaled nitric oxide in asthma is mainly derived from the lower respiratory tract. Am J Respir Crit Care Med, 153:1773-80.

Kharitonov SA, Yates D, Robbins RA, et al. 1994. Increased nitric oxide in exhaled air of asthmatic patients. Lancet, 343:133-5.

Jones SL, Kittelson J, Cowan JO, et al. 2001. The predictive value of exhaled nitric oxide measurements in assessing changes in asthma control. Am J Respir Crit Care Med, 164:738-43.

Lee DK, Gray RD, Lipworth BJ. 2003. Adenosine monophosphate bronchial provocation and the actions of asthma therapy. Clin Exp Allergy, 33:287-94.

Leuppi JD, Salome CM, Jenkins CR, et al. 2001. Predictive markers of asthma exacerbation during stepwise dose reduction of inhaled corticosteroids. Am J Respir Crit Care Med, 163:406-12.

Lipworth BJ. 1999. Systemic adverse effects of inhaled corticosteroid therapy: a systematic review and meta-analysis. Arch Intern Med, 159:941-55.

Meijer RJ, Postma DS, Kauffman HF, et al. 2002. Accuracy of eosinophils and eosinophil cationic protein to predict steroid improvement in asthma. Clin Exp Allergy, 32:1096-103.

O’Connor BJ, Ridge SM, Barnes PJ, et al. 1992. Greater effect of inhaled budesonide on adenosine $5^{\prime}$-monophosphate-induced than on sodiummetabisulfite-induced bronchoconstriction in asthma. Am Rev Respir Dis, 146:560-4.

Parameswaran K, Hargreave FE. 2001. The use of sputum cell counts to evaluate asthma medications. Br J Clin Pharmacol, 52:121-8.

Pauwels RA, Lofdahl CG, Postma DS, et al. 1997. Effect of inhaled formoterol and budesonide on exacerbations of asthma. Formoterol and Corticosteroids Establishing Therapy (FACET) International Study Group. N Engl J Med, 337:1405-11.

Perpina M, Pellicer C, de Diego A, et al. 1993. Diagnostic value of the bronchial provocation test with methacholine in asthma. A Bayesian analysis approach. Chest, 104:149-54.

Ramsdell JW, Nachtwey FJ, Moser KM. 1982. Bronchial hyperreactivity in chronic obstructive bronchitis. Am Rev Respir Dis, 126:829-32.

Roberts JA, Bradding P, Britten KM, et al. 1999. The long-acting beta2agonist salmeterol xinafoate: effects on airway inflammation in asthma. Eur Respir J, 14:275-82.
Robinson DS, Bentley AM, Hartnell A, et al. 1993. Activated memory T helper cells in bronchoalveolar lavage fluid from patients with atopic asthma: relation to asthma symptoms, lung function, and bronchial responsiveness. Thorax, 48:26-32.

Sippel JM, Holden WE, Tilles SA, et al. 2000. Exhaled nitric oxide levels correlate with measures of disease control in asthma. J Allergy Clin Immunol, 106:645-50.

Sont JK, Willems LN, Bel EH, et al. 1999. Clinical control and histopathologic outcome of asthma when using airway hyperresponsiveness as an additional guide to long-term treatment. The AMPUL Study Group. Am J Respir Crit Care Med, 159: 1043-51.

Taylor DA, Jensen MW, Kanabar V, et al. 1999. A dose-dependent effect of the novel inhaled corticosteroid ciclesonide on airway responsiveness to adenosine- $5^{\prime}$-monophosphate in asthmatic patients. Am J Respir Crit Care Med, 160:237-43.

Van Den Berge M, Meijer RJ, Kerstjens HA, et al. 2001. PC(20) adenosine $5^{\prime}$-monophosphate is more closely associated with airway inflammation in asthma than PC(20) methacholine. Am J Respir Crit Care Med, 163:1546-50.

van Den Toorn LM, Prins JB, Overbeek SE, et al. 2000. Adolescents in clinical remission of atopic asthma have elevated exhaled nitric oxide levels and bronchial hyperresponsiveness. Am J Respir Crit Care Med, 162:953-7.

Vignola AM, Chanez P, Campbell AM, et al. 1998. Airway inflammation in mild intermittent and in persistent asthma. Am J Respir Crit Care Med, 157:403-9.

Warke TJ, Fitch PS, Brown V, et al. 2002. Exhaled nitric oxide correlates with airway eosinophils in childhood asthma. Thorax, 57:383-7.

Wardlaw AJ. 1999. Molecular basis for selective eosinophil trafficking in asthma: a multistep paradigm. J Allergy Clin Immunol, 104:917-26.

Wardlaw AJ, Dunnette S, Gleich GJ, et al. 1988. Eosinophils and mast cells in bronchoalveolar lavage in subjects with mild asthma. Relationship to bronchial hyperreactivity. Am Rev Respir Dis, 137: $62-9$.

Wever AM, Wever-Hess J, Hensgens HE, et al. 1994. Serum eosinophil cationic protein (ECP) in chronic asthma. Relationship to spirometry, flow-volume curves, PC20, and exacerbations. Respir Med, 88: 613-21.

Wilson AM, Lipworth BJ. 2000. Dose-response evaluation of the therapeutic index for inhaled budesonide in patients with mild-tomoderate asthma. Am J Med, 108:269-75.

Yan K, Salome CM, Woolcock AJ. 1985. Prevalence and nature of bronchial hyperresponsiveness in subjects with chronic obstructive pulmonary disease. Am Rev Respir Dis, 132:25-9. 